\title{
Assessment of the Changes in Mitochondrial Gene Polymorphism in Ulcerative Colitis and the Etiology of Ulcerative Colitis-associated Colorectal Cancer
}

\author{
TOSHIAKI TANAKA ${ }^{*}$, TAKASHI KOBUNAI ${ }^{2 *}$, YOKO YAMAMOTO ${ }^{1}$, KOJI MURONO $^{1}$, SHIGENBU EMOTO $^{1}$, \\ MASAYA HIYOSHI ${ }^{1}$, MANABU KANEKO ${ }^{1}$, KAZUHITO SASAKI ${ }^{1}$, YASUTAKA SHUNO ${ }^{1}$, TAKESHI NISHIKAWA ${ }^{1}$, \\ KEISUKE HATA ${ }^{1}$, KAZUSHIGE KAWAI ${ }^{1}$, HIROAKI NOZAWA ${ }^{1}$ and SOICHIRO ISHIHARA ${ }^{1}$ \\ ${ }^{1}$ Department of Surgical Oncology, the University of Tokyo, Tokyo, Japan; \\ ${ }^{2}$ Translational Research Laboratory, Taiho Pharmaceutical Co., Ltd., Tokyo, Japan
}

\begin{abstract}
Background: Mitochondria are energy-producing organelles, and dysfunction in these organelles causes various types of disease. Although several studies have identified mutations in nuclear DNA that are associated with the etiology of ulcerative colitis $(U C)$, information regarding mitochondrial DNA (mtDNA) in UC is limited. This study aimed to investigate the mitochondrial DNA polymorphism underlying the etiology of UC and UC-associated colorectal cancer. Materials and Methods: Next-generation sequencing was performed to assess mitochondrial DNA mutations in 12 patients with UC-associated cancer. The mtDNA mutations in the non-neoplastic mucosa, tumor tissues, and healthy controls were compared. Results: The incidence of mutations of nicotinamide adenine dinucleotide phosphate ubiquinone oxidase subunit, ATP synthetase, and tRNA was higher in non-neoplastic mucosa in those with UC compared with the healthy controls. However, no statistically significant differences were observed in mutations between the tumor tissues and non-neoplastic mucosa in UC. Conclusion: Significant mutations in mtDNA were observed in the nonneoplastic mucosa of patients with UC-associated cancer.
\end{abstract}

Ulcerative colitis (UC) is characterized by chronic mucosal inflammation. A previous meta-analysis revealed that longstanding UC leads to the development of UC-associated cancer, with a cumulative incidence rate of $2 \%$ at 10 years, $8 \%$ at 20 years, and $18 \%$ at 30 years (1). The outcome of UC

\footnotetext{
*These Authors contributed equally to this study.

Correspondence to: Toshiaki Tanaka, MD, Ph.D., Department of Surgical Oncology, University of Tokyo, Tokyo, Japan. E-mail: toshi-t@venus.dti.ne.jp
}

Key Words: Ulcerative colitis, carcinogenesis, mtDNA. is largely influenced by the management of UC-associated cancer, and its risk is also correlated to the extent and severity of inflammation. Therefore, the disease must be controlled to improve outcomes. In addition to clinical management, the mechanism underlying inflammation and carcinogenesis must be elucidated. Novel insights into the molecular mechanism can lead to novel therapeutic strategies. From this perspective, we previously assessed the molecular changes in inflammation and carcinogenesis and found that the DNA copy numbers and expression level of RUNX family transcription factor 3 (RUNX3) were lower in non-neoplastic rectal mucosa in cancer-free patients with UC than in patients with UC-associated cancer (2). In another study, we used 20 candidate nuclear genes to establish a predictive model for UC-associated cancer, which achieved an accuracy rate of $83 \%$ and a negative predictive value of $100 \%$ (3). Along with these efforts, we obtained new insights into mutational changes in nuclear DNA (nuDNA) during inflammation and carcinogenesis; however, only few studies have assessed the role of mitochondrial DNA (mtDNA) with a focus on its potential as a new target for various diseases.

The mitochondria play an important role in intracellular energy production via oxidative phosphorylation and in the development of mitochondrial apoptosis (4). Alterations in mtDNA result in defective cellular functioning. mtDNA can cause more damage than nuDNA because it lacks histones and potent DNA-repair systems, and this alteration is observed in various tissues, such as those in several tumor types, in elderly individuals, and even in normal tissues (58). In the inflammatory environment of the UC mucosa, mtDNA is susceptible to damage; however, only few reports have assessed genetic and epigenetic changes in the mtDNA of patients with UC.

In this study, a preliminary investigation of mitochondrial genetic differences among healthy controls, UC nonneoplastic mucosal, and neoplastic tissues was conducted to 
Table I. All eight genes that were hypermutated in mitochondrial DNA in non-neoplastic mucosa from patients with ulcerative colitis (UC) encoded energy-producing proteins.

\begin{tabular}{|c|c|c|c|c|c|}
\hline \multirow[t]{2}{*}{ Position } & \multirow[b]{2}{*}{ Gene symbol } & \multirow[b]{2}{*}{ Description } & \multicolumn{2}{|c|}{ mtSNP, variant/wild } & \multirow[t]{2}{*}{$p$-Value } \\
\hline & & & $\begin{array}{l}\text { Healthy } \\
\text { control }\end{array}$ & $\begin{array}{l}\text { Non-neoplastic } \\
\text { UC mucosa }\end{array}$ & \\
\hline 310 & Non-coding region & & $53 / 3,480$ & $8 / 4$ & $4.09697 \mathrm{E}-10$ \\
\hline 3010 & $M T-R N R 2$ & $\begin{array}{l}\text { Mitochondrially encoded } 16 \mathrm{~S} \text { ribosomal } \\
\text { RNA (RNR2), ribosomal RNA }\end{array}$ & $1,259 / 2,293$ & $12 / 0$ & 0.000744726 \\
\hline 3106 & $M T-R N R 2$ & $\begin{array}{l}\text { Mitochondrially encoded } 16 \text { S ribosomal } \\
\text { RNA (RNR2), ribosomal RNA }\end{array}$ & $0 / 3,552$ & $12 / 0$ & $2.1145 \mathrm{E}-32$ \\
\hline 4883 & $M T-N D 2$ & $\begin{array}{l}\text { Core subunit of the mitochondrial membrane } \\
\text { respiratory chain NADH dehydrogenase }\end{array}$ & $1,396 / 2,156$ & $12 / 0$ & 0.002556753 \\
\hline 5178 & $M T-N D 2$ & $\begin{array}{l}\text { Core subunit of the mitochondrial membrane } \\
\text { respiratory chain NADH dehydrogenase }\end{array}$ & $1,396 / 2,156$ & $12 / 0$ & 0.002556753 \\
\hline 8414 & $M T-A T P 8$ & $\begin{array}{l}\text { Mitochondrially encoded ATP synthase } \\
\text { membrane subunit } 8\end{array}$ & $1,254 / 2,298$ & $12 / 0$ & 0.000710174 \\
\hline 14668 & $M T-N D 6$ & $\begin{array}{l}\text { Mitochondrially encoded NADH:ubiquinone } \\
\text { oxidoreductase core subunit } 6\end{array}$ & $19 / 66$ & $1,270 / 2,282$ & 0.00082623 \\
\hline 16129 & $M T-T P$ & Mitochondrially encoded tRNA proline & $830 / 2,722$ & $11 / 1$ & 0.000206171 \\
\hline
\end{tabular}

mtSNP: Mitochondrial genome single nucleotide polymorphisms.

elucidate the underlying mitochondrial roles in UCassociated carcinogenesis.

\section{Materials and Methods}

Study participants and sample selection. All samples were obtained from patients with UC treated at the Department of Surgical Oncology, University of Tokyo Hospital, Tokyo, Japan. The patients provided written informed consent for the use of their specimens prior to recruitment. This study was approved by the Ethics Committee of University of Tokyo Hospital (approval no.: G3552). In total, 12 patients were recruited for this study. All patients underwent surgery for pathologically confirmed UC-associated cancer, and the resected specimens were used for analysis.

Sample collection and DNA extraction. All samples were obtained both from non-neoplastic and neoplastic rectal mucosae during routine clinical practice, as previously reported (3). At least $1 \mathrm{~mm}^{3}$ of mucosal tissue was obtained from either biopsy tissues during colonoscopic surveillance or from surgically resected specimens (9). The tissues were snap-frozen via immersion in liquid nitrogen and were stored at $-80^{\circ} \mathrm{C}$ until DNA extraction using QIAamp DNA Mini Kit (QIAGEN, Hilden, Germany). The quantity and integrity of the DNA samples were assessed via fluorometric quantitation (Qubit $^{\mathrm{TM}}$ Quantitative Fluorimeter; Thermo Fisher Scientific, Waltham, MA, USA) using a Tape Station 4200 with a highsensitivity DNA kit (Agilent Technologies, Santa Clara, CA, USA).

Next-generation sequencing (NGS). QIAseq Targeted DNA Panel (Human Mitochondria Panels; QIAGEN), an enrichment system that targets 222 amplicons covering the entire mitochondrial genome to facilitate digital DNA sequencing using molecular barcodes, was used for NGS library preparation. Briefly, $80 \mathrm{ng}$ of each DNA sample was enzymatically fragmented, and adapter sequences were added to the ends. Each original DNA molecule was assigned a unique sequence [a unique molecular identifier (UMI), which is a 12-base fully random sequence (i.e. a molecular barcode)]. The fragmented DNA was subjected to several cycles of targeted polymerase chain reaction (PCR) using one region-specific primer and one universal primer. A universal PCR was ultimately performed to amplify the library and add platform-specific adapter sequences and additional sample indices. The enriched libraries were quantified using real-time PCR and the QIAseq Library Quant Array Kit (QIAGEN). Specimens with a molarity of $4 \mathrm{nM}$ were subjected to cluster generation in a flow cell, and paired-end sequencing for 300 cycles using the MiSeq Reagent Kit version 2 in a MiSeq sequencer platform (Illumina Inc., San Diego, CA, USA) was performed. The resulting fastq files were uploaded to QIAGEN's data analysis portal pipeline for mapping to the reference mitochondrial genome (NC_012920) and for UMI counting, read trimming, and variant identification (http:// www.qiagen.com/us/shop/genes-and-pathways/data-analysis-centeroverviewpage/)

Control data for mtDNA mutations. To reduce the effect of aging or other potential diseases on mtDNA, mtDNA data from a large number of Japanese individuals who were considered as controls were used. In relation to this, the mitochondrial genome data obtained from Tohoku Medical Megabank (https://www.megabank. tohoku.ac.jp/) were utilized, which included data about mitochondrial genome single nucleotide polymorphisms from 3,552 controls.

Statistical analysis. The mtDNA mutation rates were compared between the referral data of healthy Japanese individuals and the data of non-neoplastic mucosa from patients with UC to identify the mutational changes associated with UC. In addition, in order to identify the genetic changes during UC-associated carcinogenesis, 


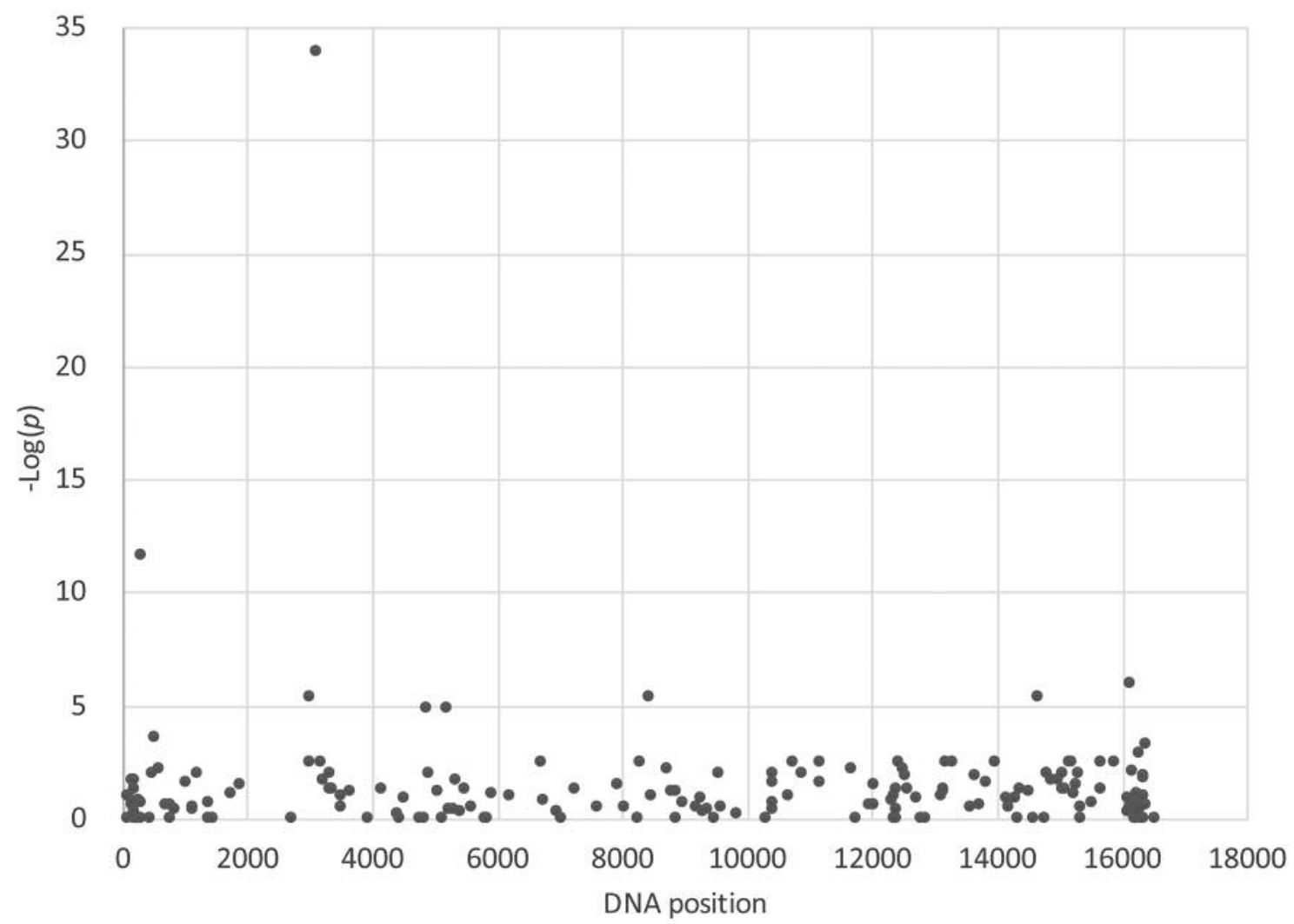

Figure 1. The difference in mutation between healthy controls and non-neoplastic mucosa from patients with ulcerative colitis (UC)-associated colorectal cancer. The X-axis shows positions in mitochondrial DNA, and the Y-axis indicates Bonferroni-corrected p-values as -log(p). Values above 3 correspond to Bonferroni-corrected values of $p<0.001$. All eight positions showed different mutational rates in non-neoplastic UC mucosa.

the mtDNA mutation status was compared between non-neoplastic and neoplastic mucosae in patients with UC. Fisher's exact test was used to compare the rates of mutational changes in mtDNA between groups.

In this study, hundreds of mtDNA mutations were observed in the limited number of patients. To guarantee statistical reliability, the Bonferroni method was used when comparing the data of patients and controls from the Tohoku Megabank. All analyses were performed using $\mathrm{R}$ version 3.5.1.

\section{Results}

Mutational changes in UC non-neoplastic mucosa. Mutational changes were detected in 182 positions located generally around the whole mitochondrial genome in the non-neoplastic epithelium of 12 patients with UC-associated colorectal cancer (CRC). Next, Fisher's exact test was used to compare the mtDNA mutations between the healthy controls from the TOHOKU Megabank and UC non-neoplastic mucosa in the 182 positions. In this step, the Bonferroni method was used. The original $p$-values calculated using the Fisher's exact test were multiplied by 182 (the number of mitochondrial genome single nucleotide polymorphisms) and was used as Bonferroni-corrected $p$-value. Figure 1 shows the distribution of the positions plotted on the $\mathrm{X}$-axis and the logarithm Bonferroni-corrected $p$-values plotted on the Y-axis. Statistically significant differences were observed in eight positions in mtDNA mutations between the UC mucosa and healthy controls (Bonferroni-corrected $p<0.01$ ). These positions coded mitochondrial ribosomal RNA, NADH ubiquinone dehydrogenase, and mitochondrial ATP synthetase, $\mathrm{NADH}$ ubiquinone oxidoreductase and mitochondrially encoded tRNA proline (Table I).

Mutational changes in UC-associated CRC. To elucidate mutational changes during the development of UCassociated cancer, we compared the mtDNA mutations in 182 positions between the non-neoplastic mucosa and tumor tissue of the patients with UC-associated CRC. We found identical rates of mtDNA mutation in 109 (59.9\%), increased mutational rates in tumor tissues in 59 (32.4\%), and decreased mutational rates in $14(7.7 \%)$ positions. As shown in Figure 2, there was no statistically significant difference 


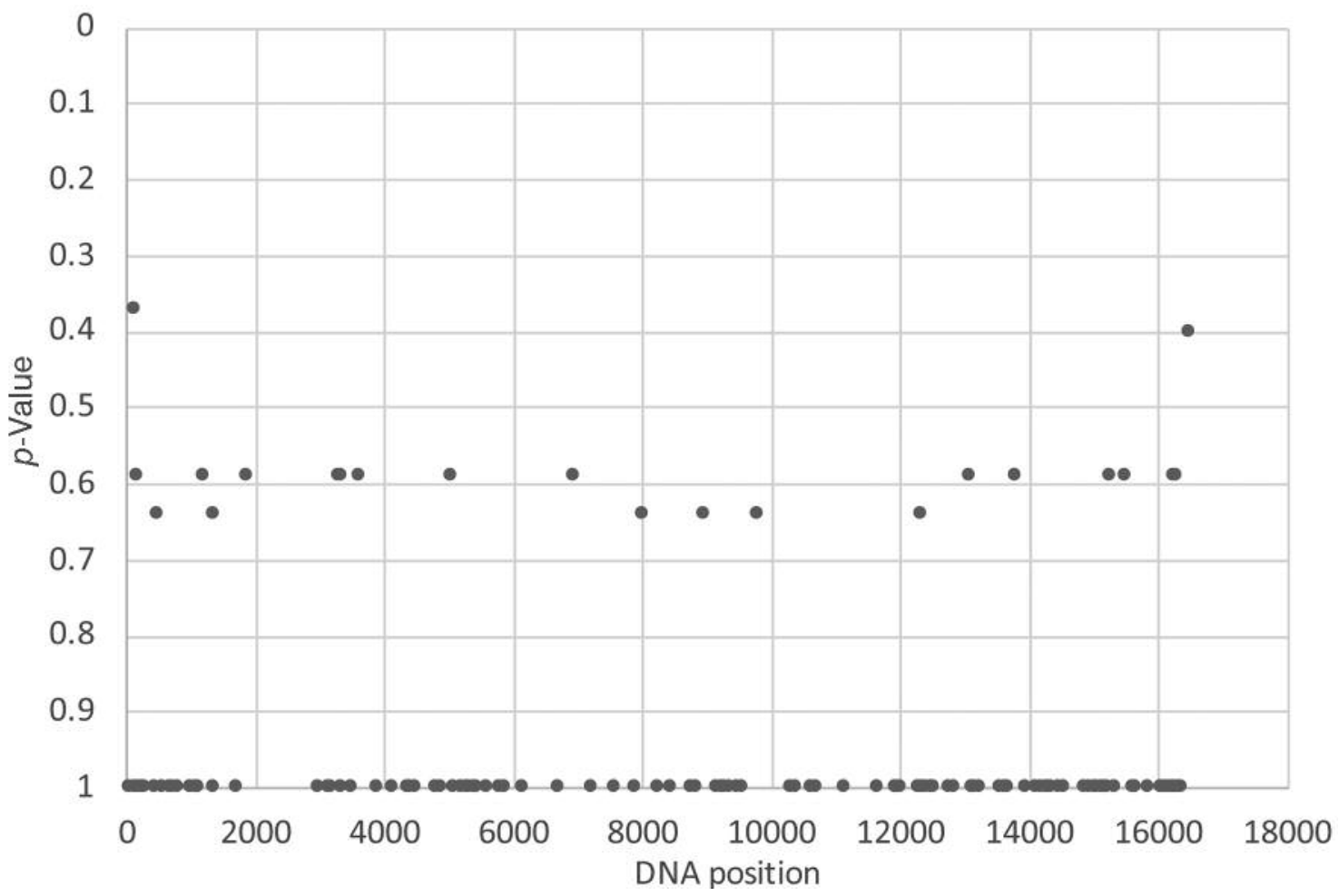

Figure 2. Comparison of mutations between non-neoplastic mucosa and cancer tissue from patients with ulcerative colitis. No additional mutation was observed in cancer tissues compared to non-neoplastic epithelium.

noted in the mutations between the non-neoplastic mucosa and tumoral tissue, which indicated the absence of significant additional mutations in the mtDNA.

\section{Discussion}

The etiology of inflammatory bowel diseases is multifocal. That is, it involves several factors, such as the environment, microbiota, epithelial barrier dysfunction, perturbed immune systems, cellular oxidative stress, and genetic alterations (1015). Among them, thus far, the genetic changes in nuDNA $(16,17)$ have been the main focus, only a few studies about mtDNA having been conducted (18). In this study, we elucidated the genetic changes in mtDNA that might be correlated to the etiology of UC. Two important findings were obtained. Firstly, mutational changes in mtDNA correlated to energy production were observed in the nonneoplastic mucosa of patients with UC-associated CRC compared to healthy controls. This indicates that changes in mtDNA may be involved in the development of UCassociated cancer. Secondly, these changes were already evident in non-neoplastic mucosa of these patients, and no additional changes were detected in the cancer epithelium. This finding indicates that UC can be identified via sampling of non-neoplastic UC epithelium, rather than cancer tissue, which is challenging to use as it has flat morphology and the surrounding mucosa is inflamed.

The mitochondria are small intracellular organelles that have essential roles in cellular energy production. The signaling pathways established by communicating with the nucleus and other intracellular components are mediated by various molecules, such as reactive oxygen species (ROS), calcium ion, and other metabolites (19-24). With respect to $\mathrm{UC}$, the mitochondrial damage in patients with UC was assessed, and an increased plasma level of circulating mtDNA fragments was observed in UC patients compared to healthy controls. Furthermore, the severity of UC was positively correlated to plasma mtDNA fragment level (25). This result supports the hypothesis that mitochondrial damage is involved in the etiology of UC.

Based on our initial findings, the genetic changes involved mitochondrial energy production through mitochondrial ATP synthetase and NADH ubiquinone oxidoreductase, and NADH dehydrogenase. The mechanism associated with mitochondrial energy production that mediates UC has been gradually elucidated. Recently, ROS came into consideration as a key molecule that mediates epithelial permeability, inflammation, and the activity of macrophages in the intestine. Mitochondrial 
ROS originates from both epithelial cells and macrophages. Arthur et al. examined the gut barrier function in dextran sodium sulfate-induced colitis in mice and observed reduced bacterial internalization and transcytosis by administering mitochondria-targeted antioxidant (MTA) (26). Their findings indicated that epithelial permeability is sustained by the energy of mitochondrial ROS, which was blocked by MTA. Moreover, the systemic delivery of MTA in murine colitis reduced disease severity, and mitochondrial ROS may be a key molecule mediating disease severity.

Another key molecule involved in mucosal inflammation is mitochondrial ATP synthetase. Laura et al. showed that the partial inhibition of ATP synthetase in the intestine of transgenic mice triggered an anti-inflammatory response via nuclear factor kappa-light-chain-enhancer of activated Bcells activation that was mediated by mitochondrial ROS (19). Mitochondrial energy metabolism has an essential role in controlling the inflammatory activity of macrophages. Macrophages are other key players in mucosal inflammation, which is also mediated by mitochondria energy production (27-33). Our findings of genetic changes involving mitochondrial energy production supports the notion that mitochondrial energy production has an essential role in the etiology of UC.

The risk of UC-associated cancer is another problem associated with chronic UC. To detect neoplasia at an early stage, we performed colonoscopy surveillance. To improve the detection rate, we modified the colonoscopy procedure, which included induction of chromo-endoscopy or targeted or nontargeted biopsy $(34,35)$. However, the early detection of neoplastic lesions is considered challenging due to the characteristics of the neoplasia, such as a flat mucosal lesion, multifocal development, and uneven surrounding mucosa. Therefore, UC-associated cancer would be better detected by measuring the genetic changes in non-neoplastic mucosa, rather than visualizing the neoplasia itself. In relation to this, we detected 20 candidate genes in nuDNA to discriminate patients with UC-associated cancer in a previous study (3). In addition, increased copy number variation of mtDNA and increased expression of nuclear genes related to mitochondrial energy metabolism are considered the predictive markers of UCassociated cancer (9).

Our second finding provided an important insight in addition to information provided in previous studies. In this study, the genetic differences between non-neoplastic mucosa and tumor tissue from the same patient were examined, and no statistically significant differences were found. This indicates that mitochondrial genetic changes correlated to UC-associated cancer also existed in non-neoplastic mucosa. Therefore, we do not have to utilize cancer tissue for detection as it is challenging to use. Rather, non-neoplastic tissue can be used for colonoscopy surveillance in order to identify patients with UC-associated CRC. The improvement in detecting patients with UC-associated CRC at an early stage would contribute to better outcomes of the disease, which is more malignant than sporadic CRC.

In the study of UC, the enrollment of a large number of participants is often challenging, especially for UCassociated CRC. Thus, the inclusion of a small number of participants is a limitation. To overcome this problem, we used data from a large number of patients from the Tohoku Megabank for control samples, and we used the Bonferroni method when examining p-values. This procedure might have strengthened the reliability of our analysis. Another limitation was the lack of data about the characteristics of patients and the analysis of heteroplastic mtDNA mutation. Thus, these problems should be addressed in future studies.

\section{Conclusion}

This preliminary study showed significant mtDNA mutational changes in UC non-neoplastic mucosa compared to healthy controls, while no significant additional alteration was observed in associated tumor tissues.

\section{Conflicts of Interest}

The Authors have no conflicts of interest concerning this study.

\section{Authors' Contributions}

Toshiaki Tanaka and Takashi Kobunai planned the experimental design. Takashi Kobunai analyzed the samples from patients. Toshiaki Tanaka and Takashi Kobunai assessed the result. Toshiaki Tanaka wrote the article. All other co-authors collected the samples from the patients' specimens.

\section{Acknowledgements}

This work was performed in collaboration with Taiho Pharmaceutical Co. Ltd., and the sample analysis was partly supported by Translational Research Laboratory, Taiho Pharmaceutical Co., Ltd.

\section{References}

1 Eaden JA, Abrams KR and Mayberry JF: The risk of colorectal cancer in ulcerative colitis: A meta-analysis. Gut 48(4): 526-535, 2001. PMID: 11247898. DOI 10.1136/gut.48.4.526

2 Watanabe T, Kobunai T, Ikeuchi H, Yamamoto Y, Matsuda K, Ishihara $\mathrm{S}$, Nozawa $\mathrm{K}$, Inuma $\mathrm{H}$, Kanazawa $\mathrm{T}$, Tanaka $\mathrm{T}$, Yokoyama T, Konishi T, Eshima K, Ajioka Y, Hibi T, Watanabe M, Muto T and Nagawa H: Runx3 copy number predicts the development of UC-associated colorectal cancer. Int J Oncol 38(1): 201-207, 2011. PMID: 21109941

3 Watanabe T, Kobunai T, Yamamoto Y, Ikeuchi H, Matsuda K, Ishihara S, Nozawa $\mathrm{K}$, Iinuma $\mathrm{H}$, Kanazawa $\mathrm{T}$, Tanaka $\mathrm{T}$, Yokoyama T, Konishi T, Eshima K, Ajioka Y, Hibi T, Watanabe M, Muto T and Nagawa H: Predicting ulcerative colitis-associated colorectal cancer using reverse-transcription polymerase chain 
reaction analysis. Clin Colorectal Cancer 10(2): 134-141, 2011 PMID: 21859567. DOI 10.1016/j.clcc.2011.03.011

4 Wallace DC: The mitochondrial genome in human adaptive radiation and disease: On the road to therapeutics and performance enhancement. Gene 354: 169-180, 2005. PMID: 16024186. DOI 10.1016/j.gene.2005.05.001

5 Penta JS, Johnson FM, Wachsman JT and Copeland WC: Mitochondrial DNA in human malignancy. Mutat Res 488(2): 119-133, 2001. PMID: 11344040. DOI 10.1016/s1383-5742(01) 00053-9

6 Birch-Machin MA: The role of mitochondria in ageing and carcinogenesis. Clin Exp Dermatol 31(4): 548-552, 2006. PMID: 16716161. DOI 10.1111/j.1365-2230.2006.02161.x

7 Chen T, He J, Shen L, Fang H, Nie H, Jin T, Wei X, Xin Y, Jiang Y, Li H, Chen G, Lu J and Bai Y: The mitochondrial DNA 4.977-bp deletion and its implication in copy number alteration in colorectal cancer. BMC Med Genet 12: 8, 2011. PMID: 21232124. DOI 10.1186/1471-2350-12-8

8 Abnet CC, Huppi K, Carrera A, Armistead D, McKenney K, Hu $\mathrm{N}$, Tang ZZ, Taylor PR and Dawsey SM: Control region mutations and the 'common deletion' are frequent in the mitochondrial DNA of patients with esophageal squamous cell carcinoma. BMC Cancer 4: 30, 2004. PMID: 15230979. DOI 10.1186/1471-2407-4-30

9 Tanaka T, Kobunai T, Yamamoto Y, Murono K, Otani K, Yasuda K, Nishikawa T, Kiyomatsu T, Kawai K, Hata K, Nozawa H, Ishihara $\mathrm{S}$ and Watanabe T: Increased copy number variation of mtDNA in an array-based digital PCR assay predicts ulcerative colitis-associated colorectal cancer. In Vivo 31(4): 713-718, 2017. PMID: 28652445. DOI 10.21873/invivo.11119

10 Rosa A, Abrantes P, Sousa I, Francisco V, Santos P, Francisco $\mathrm{D}$, Xavier JM and Oliveira SA: Ulcerative colitis is under dual (mitochondrial and nuclear) genetic control. Inflamm Bowel Dis 22(4): 774-781, 2016. PMID: 26926037. DOI 10.1097/MIB.000 0000000000694

11 Danese S, Sans M and Fiocchi C: Inflammatory bowel disease: The role of environmental factors. Autoimmun Rev 3(5): 394400, 2004. PMID: 15288007. DOI 10.1016/j.autrev.2004.03.002

12 Jena G, Trivedi PP and Sandala B: Oxidative stress in ulcerative colitis: An old concept but a new concern. Free Radic Res 46(11): 1339-1345, 2012. PMID: 22856328. DOI 10.3109/ 10715762.2012 .717692

$13 \mathrm{Zhu} \mathrm{H}$ and Li YR: Oxidative stress and redox signaling mechanisms of inflammatory bowel disease: Updated experimental and clinical evidence. Exp Biol Med 237(5): 474480, 2012. PMID: 22442342. DOI 10.1258/ebm.2011.011358

14 Jostins L, Ripke S, Weersma RK, Duerr RH, McGovern DP, Hui KY, Lee JC, Schumm LP, Sharma Y, Anderson CA, Essers J, Mitrovic M, Ning K, Cleynen I, Theatre E, Spain SL, Raychaudhuri S, Goyette P, Wei Z, Abraham C, Achkar JP, Ahmad T, Amininejad L, Ananthakrishnan AN, Andersen V, Andrews JM, Baidoo L, Balschun T, Bampton PA, Bitton A, Boucher G, Brand S, Buning C, Cohain A, Cichon S, D'Amato M, De Jong D, Devaney KL, Dubinsky M, Edwards C, Ellinghaus D, Ferguson LR, Franchimont D, Fransen K, Gearry R, Georges M, Gieger C, Glas J, Haritunians T, Hart A, Hawkey C, Hedl M, Hu X, Karlsen TH, Kupcinskas L, Kugathasan S, Latiano A, Laukens D, Lawrance IC, Lees CW, Louis E, Mahy G, Mansfield J, Morgan AR, Mowat C, Newman W, Palmieri O, Ponsioen CY, Potocnik U, Prescott NJ, Regueiro M, Rotter JI, Russell RK, Sanderson JD,
Sans M, Satsangi J, Schreiber S, Simms LA, Sventoraityte J, Targan SR, Taylor KD, Tremelling M, Verspaget HW, De Vos M, Wijmenga C, Wilson DC, Winkelmann J, Xavier RJ, Zeissig S, Zhang B, Zhang CK, Zhao H, International IBDGC, Silverberg MS, Annese V, Hakonarson H, Brant SR, Radford-Smith G, Mathew CG, Rioux JD, Schadt EE, Daly MJ, Franke A, Parkes M, Vermeire S, Barrett JC and Cho JH: Host-microbe interactions have shaped the genetic architecture of inflammatory bowel disease. Nature 491(7422): 119-124, 2012. PMID: 23128233. DOI 10.1038 /nature 11582

15 Colombel JF and Mahadevan U: Inflammatory bowel disease 2017: Innovations and changing paradigms. Gastroenterology 152(2): 309-312, 2017. PMID: 27960091. DOI 10.1053/ j.gastro.2016.12.004

16 Tanaka T, Kobunai T, Yamamoto Y, Emoto S, Murono K, Kaneko M, Sasaki K, Otani K, Nishikawa T, Kawai K, Hata K, Nozawa $\mathrm{H}$ and Watanabe T: Colitic cancer develops through mutational alteration distinct from that in sporadic colorectal cancer: A comparative analysis of mutational rates at each step. Cancer Genomics Proteomics 14(5): 341-348, 2017. PMID: 28871001. DOI 10.21873/cgp.20044

17 Tsai JH, Rabinovitch PS, Huang D, Small T, Mattis AN, Kakar $S$ and Choi WT: Association of aneuploidy and flat dysplasia with development of high-grade dysplasia or colorectal cancer in patients with inflammatory bowel disease. Gastroenterology 153(6): 1492-1495 e1494, 2017. PMID: 28843957. DOI 10.1053/j.gastro.2017.08.031

18 Baker KT, Nachmanson D, Kumar S, Emond MJ, Ussakli C, Brentnall TA, Kennedy SR and Risques RA: Mitochondrial DNA mutations are associated with ulcerative colitis preneoplasia but tend to be negatively selected in cancer. Mol Cancer Res 17(2): 488-498, 2019. PMID: 30446624. DOI 10.1158/1541-7786.MCR-18-0520

19 Formentini L, Santacatterina F, Nunez de Arenas C, Stamatakis K, Lopez-Martinez D, Logan A, Fresno M, Smits R, Murphy MP and Cuezva JM: Mitochondrial ros production protects the intestine from inflammation through functional M2 macrophage polarization. Cell Rep 19(6): 1202-1213, 2017. PMID: 28494869. DOI 10.1016/j.celrep.2017.04.036

20 Chandel NS: Evolution of mitochondria as signaling organelles. Cell Metab 22(2): 204-206, 2015. PMID: 26073494. DOI 10.1016/j.cmet.2015.05.013

21 Quiros PM, Mottis A and Auwerx J: Mitonuclear communication in homeostasis and stress. Nat Rev Mol Cell Biol 17(4): 213226, 2016. PMID: 26956194. DOI 10.1038/nrm.2016.23

22 Glancy B and Balaban RS: Role of mitochondrial $\mathrm{Ca}^{2+}$ in the regulation of cellular energetics. Biochemistry 51(14): 29592973, 2012. PMID: 22443365. DOI 10.1021/bi2018909

23 Sena LA and Chandel NS: Physiological roles of mitochondrial reactive oxygen species. Mol Cell 48(2): 158-167, 2012. PMID: 23102266. DOI 10.1016/j.molcel.2012.09.025

24 Shi L and Tu BP: Acetyl-CoA and the regulation of metabolism: Mechanisms and consequences. Curr Opin Cell Biol 33: 125131, 2015. PMID: 25703630. DOI 10.1016/j.ceb.2015.02.003

25 Boyapati RK, Dorward DA, Tamborska A, Kalla R, Ventham NT, Doherty MK, Whitfield PD, Gray M, Loane J, Rossi AG, Satsangi $\mathrm{J}$ and Ho GT: Mitochondrial DNA is a proinflammatory damage-associated molecular pattern released during active ibd. Inflamm Bowel Dis 24(10): 2113-2122, 2018. PMID: 29718255. DOI 10.1093/ibd/izy095 
26 Wang A, Keita AV, Phan V, McKay CM, Schoultz I, Lee J, Murphy MP, Fernando M, Ronaghan N, Balce D, Yates R, Dicay M, Beck PL, MacNaughton WK, Soderholm JD and McKay DM: Targeting mitochondria-derived reactive oxygen species to reduce epithelial barrier dysfunction and colitis. Am J Pathol 184(9): 2516-2527, 2014. PMID: 25034594. DOI 10.1016/ j.ajpath.2014.05.019

27 Sica A and Mantovani A: Macrophage plasticity and polarization: In vivo veritas. J Clin Invest 122(3): 787-795, 2012. PMID: 22378047. DOI 10.1172/JCI59643

28 Van den Bossche J, Baardman J, Otto NA, van der Velden S, Neele AE, van den Berg SM, Luque-Martin R, Chen HJ, Boshuizen MC, Ahmed M, Hoeksema MA, de Vos AF and de Winther MP: Mitochondrial dysfunction prevents repolarization of inflammatory macrophages. Cell Rep 17(3): 684-696, 2016. PMID: 27732846. DOI 10.1016/j.celrep.2016.09.008

29 Cramer T, Yamanishi Y, Clausen BE, Forster I, Pawlinski R, Mackman N, Haase VH, Jaenisch R, Corr M, Nizet V, Firestein GS, Gerber HP, Ferrara N and Johnson RS: Hif-1alpha is essential for myeloid cell-mediated inflammation. Cell 112(5): 645-657, 2003. PMID: 12628185. DOI 10.1016/s00928674(03)00154-5

30 Huang SC, Everts B, Ivanova Y, O'Sullivan D, Nascimento M, Smith AM, Beatty W, Love-Gregory L, Lam WY, O'Neill CM, Yan C, Du H, Abumrad NA, Urban JF, Jr., Artyomov MN, Pearce EL and Pearce EJ: Cell-intrinsic lysosomal lipolysis is essential for alternative activation of macrophages. Nat Immunol 15(9): 846-855, 2014. PMID: 25086775. DOI 10.1038/ni.2956

31 Tan Z, Xie N, Cui H, Moellering DR, Abraham E, Thannickal VJ and Liu G: Pyruvate dehydrogenase kinase 1 participates in macrophage polarization via regulating glucose metabolism. J Immunol 194(12): 6082-6089, 2015. PMID: 25964487. DOI 10.4049/jimmunol.1402469
32 Tannahill GM, Curtis AM, Adamik J, Palsson-McDermott EM, McGettrick AF, Goel G, Frezza C, Bernard NJ, Kelly B, Foley NH, Zheng L, Gardet A, Tong Z, Jany SS, Corr SC, Haneklaus M, Caffrey BE, Pierce K, Walmsley S, Beasley FC, Cummins E, Nizet V, Whyte M, Taylor CT, Lin H, Masters SL, Gottlieb E, Kelly VP, Clish C, Auron PE, Xavier RJ and O'Neill LA: Succinate is an inflammatory signal that induces IL-1beta through HIF-1alpha. Nature 496(7444): 238-242, 2013. PMID: 23535595. DOI 10.1038/nature11986

33 Vats D, Mukundan L, Odegaard JI, Zhang L, Smith KL, Morel CR, Wagner RA, Greaves DR, Murray PJ and Chawla A: Oxidative metabolism and PGC-1beta attenuate macrophagemediated inflammation. Cell Metab 4(1): 13-24, 2006. PMID: 16814729. DOI 10.1016/j.cmet.2006.05.011

34 Watanabe T, Ajioka Y, Mitsuyama K, Watanabe K, Hanai H, Nakase H, Kunisaki R, Matsuda K, Iwakiri R, Hida N, Tanaka S, Takeuchi Y, Ohtsuka K, Murakami K, Kobayashi K, Iwao Y, Nagahori M, Iizuka B, Hata K, Igarashi M, Hirata I, Kudo SE, Matsumoto T, Ueno F, Watanabe G, Ikegami M, Ito Y, Oba K, Inoue E, Tomotsugu N, Takebayashi T, Sugihara K, Suzuki Y, Watanabe $\mathrm{M}$ and Hibi T: Comparison of targeted vs random biopsies for surveillance of ulcerative colitis-associated colorectal cancer. Gastroenterology 151(6): 1122-1130, 2016. PMID: 27523980. DOI 10.1053/j.gastro.2016.08.002

35 Hata K, Watanabe T, Shinozaki M, Kojima T and Nagawa H: To dye or not to dye? That is beyond question! Optimising surveillance colonoscopy is indispensable for detecting dysplasia in ulcerative colitis. Gut 53(11): 1722, 2004. PMID: 15479703.

Received November 10, 2019

Revised November 19, 2019

Accepted November 20, 2019 